\title{
Murine mesenchymal stem cells suppress dendritic cell migration, maturation and antigen presentation
}

\author{
Karen English ${ }^{\mathrm{a}}$, Frank P. Barry ${ }^{\mathrm{b}}$, Bernard P. Mahon ${ }^{\mathrm{a}, *}$ \\ ${ }^{a}$ Mucosal Immunology Laboratory, Institute of Immunology, National University of Ireland Maynooth, Maynooth, Co. Kildare, Ireland \\ ${ }^{\mathrm{b}}$ Regenerative Medicine Institute (REMEDI), National University of Ireland, Galway, Ireland
}

Received 23 May 2007; received in revised form 4 October 2007; accepted 8 October 2007

Available online 31 October 2007

\begin{abstract}
Mesenchymal stem cells (MSC) possess a wide range of immunosuppressive functions. Among these is the ability to inhibit CD4 ${ }^{+} \mathrm{T}_{\text {cell }}$ proliferation. Dendritic cells (DC) play a role in initiating cell-mediated immunity; however, the immunosuppressive influence of MSC on professional antigen presenting cells remains unclear. DC exposed to TNF- $\alpha$ and cultured with murine MSC failed to show regular upregulation of maturation markers. Similarly, the presence of MSC abrogated the capacity of ovalbumin-pulsed DC to support antigen specific CD4 ${ }^{+} \mathrm{T}$ cell proliferation, or for DC to display an MHC class II- peptide complex recognizable by specific antibody. Interestingly, culture of MSC with DC resulted in reduced expression of CCR7 by DC following stimulation. Likewise, DC matured in the presence of MSC, showed significantly less migration to CCL19. In contrast, murine MSC prevented loss of expression of the tissue anchoring protein E-cadherin by DC. Modulation of DC maturation and function was not permanent and could be restored after removal of MSC. These data demonstrate that MSC modulate the three cardinal features of DC maturation, providing the first demonstration of MSC interference with DC migration.
\end{abstract}

(C) 2007 Elsevier B.V. All rights reserved.

Keywords: Mesenchymal stem cell; Dendritic cell; Immunosuppression; CCR7; E-cadherin

\section{Introduction}

Adult mesenchymal stem cells (MSC) are multipotent cells able to self-renew under controlled conditions. MSC may differentiate into multiple lineages including bone, fat and cartilage $[1,2]$. Usually, MSC reside in the bone marrow, and provide support for hematopoietic stem cells through the production of growth factors [3]. However, the primary function of MSC is to repair and replace damaged tissues [4-6]. These characteristics make MSC an attractive source for tissue engineering and regenerative medicine.

MSC possess an array of immunosuppressive capabilities. Various groups have demonstrated that both murine and human MSC suppress alloantigen and mitogen driven $\mathrm{T}$ cell proliferation in vitro [7-10]. Some of these functions are dependent on exogenous IFN- $\gamma[7,11,12]$. Comparable studies, investigating MSC immunosuppression of B cells, have demonstrated that

\footnotetext{
* Corresponding author. Tel.: +3531708 3835; fax: +3531 1083845 .

E-mail address: bpmahon@ nuim.ie (B.P. Mahon).
}

MSC physically hindered proliferation [9,13], likewise, MSC can inhibit NK cell proliferation and cytotoxicity $[11,14]$. Whilst these are important data, a deeper understanding of how MSC modulate $\mathrm{T}$ cell responses will be central to the development of acceptable therapies involving MSC.

Dendritic cells (DC) arise in the bone marrow and play a pivotal role in the induction of adaptive immunity. DC have the ability to initiate a primary adaptive immune response through the capture, processing and presentation of antigen to naïve $\mathrm{CD} 4^{+} \mathrm{T}$ cells, however differences in these capacities are linked to the developmental maturity of the DC. Immature DC (iDC), resident in tissue, efficiently capture antigen [15]. Exposure to stimuli such as pathogen associated molecules including LPS, bacterial DNA, or pro-inflammatory cytokines (e.g. TNF- $\alpha$ ), initiate a process termed maturation [16]. Maturing DC alter the expression of chemokine receptors including CCR7, thus becoming responsive to the lymph node derived chemokine CCL19 [17]. In addition, mature DC (mDC) downregulate E-cadherin expression, allowing migration to regional lymph nodes [18]. In the lymph node, $\mathrm{mDC}$ express high levels of MHC class II, CD80 and CD86 which play a well-described 
role in antigen presentation to $\mathrm{CD}^{+} \mathrm{T}$ cells [15]. Thus, DC maturation plays a key role in initiating $\mathrm{T}$ cell responses, and not surprisingly, many pathogens have exploited this process to evade immunity $[19,20]$.

A number of recent studies have focused on the influence of MSC on DC function [21-24]. However, data have been confounded by differences in models, technical approaches and in particular differences between MSC and DC isolation protocols [21]. At least five different murine MSC populations have been described and subtle differences in their function have been observed [10,13,25-27].

In the present study, a well-characterised MSC population and a clearly defined DC population were used to probe the interaction between these two cell types. This study demonstrates that MSC disrupt the three major functions that characterise the transition of DC from immature to mature stages; namely the upregulation of antigen presentation and co-stimulatory molecule expression, the ability to present defined antigens, and the capacity to migrate to CCL19. Collectively, these data support the hypothesis that MSC profoundly influence host immunity by modulating DC function suggesting that allogeneic MSC may not require profound immunosuppression during clinical application.

\section{Materials and methods}

\subsection{Animals}

Six-to-eight-week-old female BALB/c $\left(\mathrm{H}-2^{\mathrm{d}}\right)$, C57BL/6 (Harlan, Oxon, U.K.) and DO11.10 (H-2 $\left.{ }^{\mathrm{d}}\right)$ mice [28] were used for experiments under the guidelines of the Irish Department of Health and the approval of the research ethics committee of the National University of Ireland Maynooth.

\subsection{Isolation and culture of bone marrow derived mesenchymal stem cells}

Murine MSC were isolated and expanded using an in-house modification [7] of the method of Peister et al. [29]. Cells retained differentiation capacity as previously described [29]. All MSC were $\mathrm{MHC} \mathrm{I} \mathrm{I}^{+}, \mathrm{Sca}-1^{+}, \mathrm{CD} 44^{\text {low }}, \mathrm{CD} 106^{\text {low }}, \mathrm{MHC}$ $\mathrm{II}^{-}, \mathrm{CD} 11 \mathrm{~b}^{-}, \mathrm{CD} 11 \mathrm{c}^{-}, \mathrm{CD} 34^{-}, \mathrm{CD} 45^{-}$and $\mathrm{CD} 117^{-}$. Stem cells were used between passages 3 and 10 and rigorous purification and quality control were performed to ensure MSC purity as previously described [7].

\subsection{Dendritic cell culture}

Isolation and culture of bone marrow derived DC was carried out as previously described with minor modifications [30,31]. Briefly, immature DC were prepared by culturing cells taken from murine bone marrow (femur and tibia) in RPMI 1640 medium (Gibco-Invitrogen, Paisley, UK) supplemented with $10 \%(\mathrm{v} / \mathrm{v})$ heat inactivated, endotoxin low fetal calf serum, $1 \%$ $(\mathrm{v} / \mathrm{v})$ penicillin/streptomycin (Gibco-Invitrogen) and $1 \%(\mathrm{v} / \mathrm{v})$ L-glutamine (Gibco-Invitrogen) with either $95 \mathrm{ng} / \mathrm{ml}$ recombi- nant GMCSF/300 pg/ml IL-4 (Peprotech EC, London, UK) or by recombinant $\mathrm{J} 558$ supernatant previously shown to be equivalent in supporting DC culture [31]. Cells were cultured for $3 \mathrm{~d}$ at $37^{\circ} \mathrm{C}$, and culture medium was carefully replaced with fresh medium at this time. Cells were harvested at $6 \mathrm{~d}$ by gentle aspiration, counted, and analysed by flow cytometry. DC populations used were $>70 \% \mathrm{CD} 11 \mathrm{c}+$ with no detectable expression of Sca-1, a marker found on MSC but not DC. In maturation experiments, immature DC were seeded at $7.5 \times 10^{5} / \mathrm{ml}$ and cultured in $2 \mathrm{ml}$ cRPMI +/- $25 \mathrm{ng} / \mathrm{ml}$ TNF-( (R\&D systems, Abington, UK) as maturing agent, then co-cultured in the presence or absence of MSC or control MLE- 12 cells $\left(2.5 \times 10^{5} / \mathrm{ml}\right)$ for $24 \mathrm{~h}$ or $48 \mathrm{~h}$. Differences in adherence to tissue culture plastic by the two populations allowed a simple but reproducible technique to recover DC from co-cultures. DC were harvested by gentle aspiration from strongly adherent MSC or MLE-12 cells after 24 or $48 \mathrm{~h}$. Isolated DC were re-analysed by flow cytometry using antibodies against $\mathrm{CD} 11 \mathrm{c}$ and $\mathrm{Sca}-1$. DC re-isolated by this method were $>70 \% \mathrm{CD} 11 \mathrm{c}+$ but did not express Sca-1 $(<1 \%)$. For return of function studies, DC were similarly re-isolated from MSC coculture and re-stimulated in fresh medium with TNF- $\alpha$ for $48 \mathrm{~h}$ before use in chemotaxis assays.

\section{4. $\mathrm{CD}^{+} \mathrm{T}$ cell proliferation}

Immature DC $\left(1 \times 10^{5} / \mathrm{ml}\right)$ were cultured with $20 \mu \mathrm{g} / \mathrm{ml}$ Ovalbumin (Sigma-Aldrich) in the presence or absence of MSC (1:3 MSC: DC) for $24 \mathrm{~h}$. DC were isolated by gentle aspiration, and washed twice in culture medium. DC were then co-cultured with $4 \times 10^{5} / \mathrm{ml}$ naïve OVA-specific,

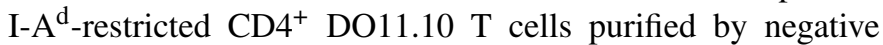
selection (R\&D Systems). Cells were cultured for $72 \mathrm{~h}$ in total with $\left[{ }^{3} \mathrm{H}\right]$ thymidine (Amersham Biosciences, Buckinghamshire, England) $(5 \mu \mathrm{Ci} / \mathrm{ml})$ added for the final $6 \mathrm{~h}$ as previously described [32]. Cells were harvested and Thymidine incorporation quantified as mean counts per minute $( \pm$ S.E. $)$ by liquid scintillation [32].

\subsection{Flow cytometry}

Cell phenotype was characterised by flow cytometry (FACSCalibur), analysed using CellQuest software (BD Biosciences, Oxford, UK). Cells were labelled with combinations of FITC or PE-conjugated antibodies against Sca-1, CD11b, CD11c, CD34, CD40, CD44, CD45, CD80, CD86, CD106, CD117, CCR7, MHC I and II or appropriate species and isotype-matched controls (eBiosciences, San Diego, CA).

\subsection{Chemotaxis}

Cell migration was performed in 24-well Transwell ${ }^{\mathrm{TM}}$ chambers (Corning Costar, Cambridge, MA) using $5 \mu \mathrm{m}$-pore size polycarbonate membranes as described [33] with minor modifications. $1 \times 10^{5}$ mature DC in serum free medium $(100 \mu \mathrm{l})$ were loaded into the upper chamber. CCL19 (100 ng/ml) (R \& D Systems) in sterile serum-free RPMI, $1 \%$ (v/v) BSA was added to the lower chamber. After $1.5 \mathrm{~h}$ incubation at $37^{\circ} \mathrm{C}, 5 \% \mathrm{CO}_{2}$, chemo- 
taxed cells were counted in three random fields of view from digital images generated using an inverted microscope (Olympus CK40, Centre valley, PA). Each assay was performed in duplicate, and repeated three times. The lower compartment of control wells contained medium alone. A chemotactic index was calculated against the basal level of DC migration to medium alone.

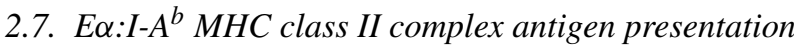 assay}

DC were incubated alone or in the presence of $10 \mu \mathrm{g} / \mathrm{ml}$ I-E $\alpha$ peptide 52-68 (ASFEAQGALANIAVDKA) (Anaspec, San Jose, CA) or vehicle buffer control in the presence or absence of MSC for $48 \mathrm{~h}$. Peptide binding was detected using the biotin-conjugated anti-I-A $\mathrm{A}^{\mathrm{b}}:$ E $\alpha$ complex-specific antibody, YAe (eBioscience) as previously described [34]. Binding of biotin-conjugated antibody was detected by PE-conjugated streptavadin (Sigma-Aldrich) and was analysed by flow cytometry (BD Biosciences). Data analysis was carried out using CellQuest software (BD Biosciences).

\subsection{Semi-quantitative RT-PCR}

DC were seeded at $6 \times 10^{5}$ cells $/ \mathrm{ml}$ in 24 -well cultures (Nunc, Rorsklide, Denmark) and either non-stimulated, or matured with TNF- $\alpha(25 \mathrm{ng} / \mathrm{ml})$ in the presence, or absence of MSC $\left(2 \times 10^{5} / \mathrm{ml}\right)$ and harvested at $24 \mathrm{~h}$ for RNA isolation using TRI Reagent ${ }^{\mathrm{TM}}$ (Molecular Research Centre, Cincinnati, $\mathrm{OH}$ ) according to manufacturer's instructions. cDNA from iDC, $\mathrm{mDC}$ or DC cultured with MSC were probed for GAPDH, CCR7 or E-cadherin. Primers pairs were: GAPDH: 5'-GGTGAAGGTCGGAGTCAACG-' 3 and 5'-CAAAGTTGTCATGGATGACC-'3; E-cadherin: 5'-GGCTGGACCGAGAGAGTT- 3 and 5'-CTGCTTGGCCTCAAAATC-' 3 ; CCR7: 5'-AGTCTTCCAGCTGCCCTACA- ${ }^{\prime} 3$ and $5^{\prime}$-CAGCCCAAGTCCTTGAAGAG-'3.

\subsection{Quantitative RT-PCR}

cDNA were analysed for the expression of murine CCR7 and E-cadherin by fluorogenic 5'- nuclease PCR assay (MJ Research Inc., Waltham, MA). cDNA (500 ng) were amplified in the presence of SYBR ${ }^{\circledR}$ Green PCR mastermix (Qiagen, West Sussex, UK). Standard curves for CCR7 and E-cadherin expression were generated by amplifying 10-fold serial dilutions of known quantities of CCR7 and E-cadherin PCR product standards. Quantification of target gene expression was obtained using sequence detector system software (MJ Research Inc., Waltham, MA).

\subsection{Western blot}

Cells were lysed in RIPA buffer (Sigma-Aldrich) and lysate resolved by $12 \%$ SDS/PAGE, then electro-transferred to nitrocellulose membranes (Amersham Biosciences, Buckinghamshire, U.K.) and blocked for $1 \mathrm{~h}$ in $5 \%(\mathrm{w} / \mathrm{v})$ non-fat milk powder/PBS with $0.05 \%$ (v/v) Tween 20. Membranes were probed with anti-mouse E-cadherin (BD Biosciences, Oxford, UK) or matched control antibody. Binding of antibody to Ecadherin was detected by horseradish peroxidase conjugated anti-mouse secondary antibody (Sigma-Aldrich) and detected by Amersham ECL Western Blotting analysis system (Amersham Biosciences).

\subsection{Statistical methods}

Results are expressed as mean \pm (S.E.). A Student's paired $t$-test was used to determine significance between the groups, $p<0.05$ was considered significant. Statistical analyses and graphical representations were performed using GraphPad Prism $^{\mathrm{TM}}$ software (GraphPad, San Diego, CA).

\section{Results}

\subsection{Murine MSC prevent TNF- $\alpha$ driven dendritic cell maturation}

DC maturation is a critical feature for the induction of adaptive immune responses, aspects of alloantigen elimination and transplant rejection. Maturation is accompanied by phenotypic changes in DC surface protein expression associated with APC competence. The capacity of MSC to modulate DC maturation driven by a robust stimulus was examined. Immature bone marrow derived CD11c ${ }^{+}$DC (iDC) expressed low levels of MHC class II and the co-stimulatory molecule CD86 (Fig. 1A), as expected, maturation by $\mathrm{TNF}-\alpha$ resulted in increased surface expression of these markers (Fig. 1A). DC are susceptible to maturation by relatively gentle manipulation, importantly coculture of immature DC with MSC did not lead to increased expression of CD86 or MHC class II, and therefore manipulation or contact between these cell types did not result in anomalous DC maturation. DC cultured with TNF- $\alpha$ were separated from strongly adherent MSC in co-cultures by gentle aspiration after $48 \mathrm{~h}$. Unlike DC exposed to TNF- $\alpha$ alone, DC cultured with TNF- $\alpha$ in the presence of MSC failed to upregulate either marker post TNF- $\alpha$ stimulation (Fig. 1A), rather DC co-cultured with MSC showed significantly reduced surface expression of MHC class II and CD86 (Fig. 1B). It was possible that co-culture of DC with MSC led to exhaustion of nutrients in cell culture medium. Therefore it might be argued that MSC modulation of DC maturation marker expression was not MSC specific and/or was merely a result of nutrient exhaustion in the culture medium. To rule out this possibility, co-cultures were repeated in which rapidly dividing transformed epithelial cells (MLE-12) replaced MSC. Co-culture of DC with MLE-12 cells did not prevent upregulation of MHC class II or CD86 suggesting that competition for nutrients or medium exhaustion was unlikely to be the mechanism of modulation (Table 1.). The presence of MSC in cultures did not increase DC apoptosis or alter cell viability. Furthermore DC removed from co-culture with MSC and re-stimulated with $\mathrm{TNF}-\alpha$ for $48 \mathrm{~h}$ showed regular upregulation of maturation markers as indicated by MHC class II (Fig. 1C). These data are consistent with the hypothesis that MSC induce 
(A)
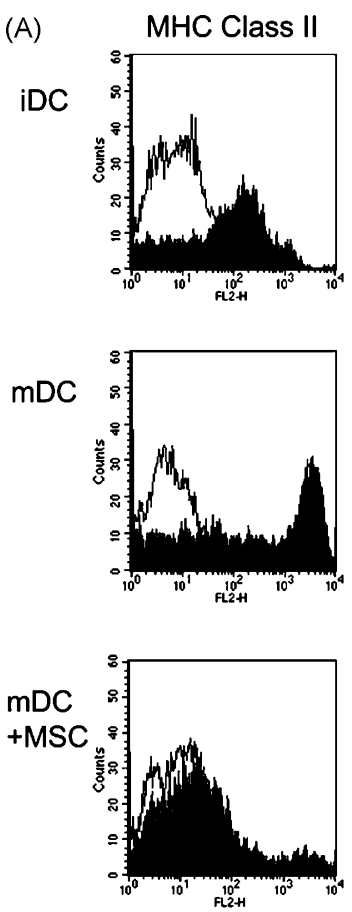
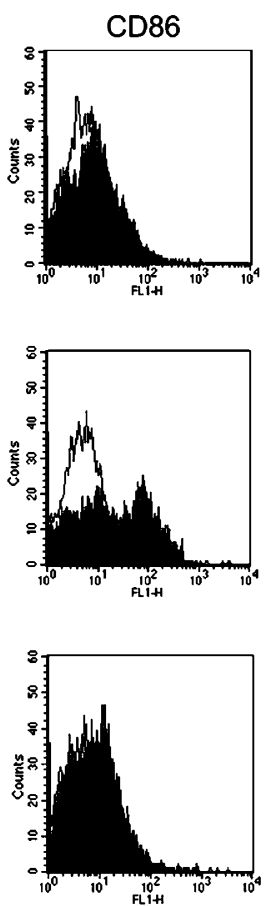

(B)
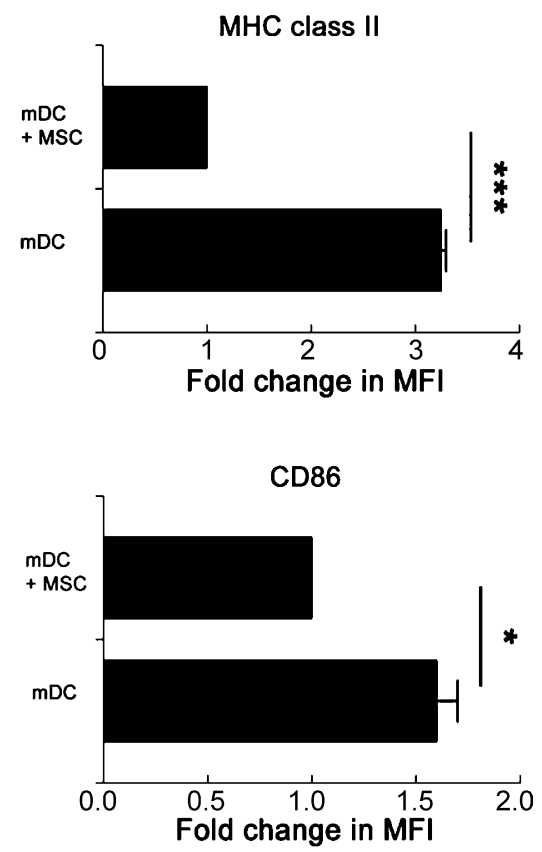

(C)
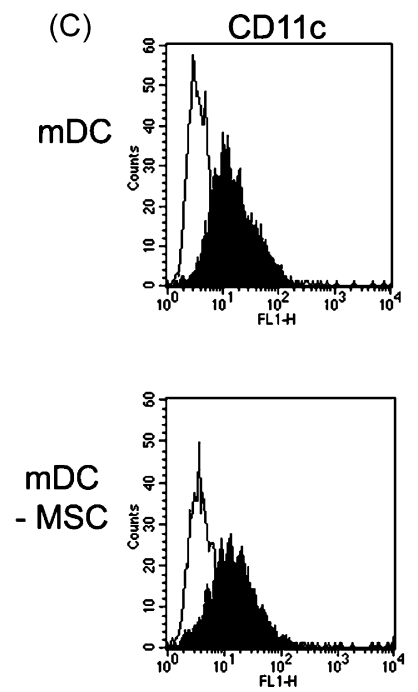
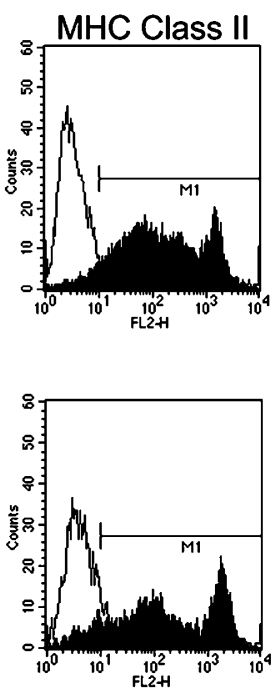

Fig. 1. Murine MSC prevent upregulation of DC maturation markers. Immature DC (iDC) were stimulated with TNF- $\alpha$ (mDC) and cultured in the presence or absence of MSC for $48 \mathrm{~h}$. DC stimulated with TNF- $\alpha$ were separated from adherent MSC in co-cultures by gentle aspiration after $48 \mathrm{~h}$ and maturation marker (MHC class II or CD86) expression (shaded) analysed by flow cytometry and compared to species and isotype-matched controls (open). Data were expressed as histograms (A) or mean fluorescence intensity (MFI) change (B). DC cultured with MSC showed significantly reduced MHC class II MFI (***, $p<0.001)$, and CD86 (*, $p<0.05)$. DC previously co-cultured with MSC, were harvested from MSC co-cultures, re-stimulated with TNF- $\alpha$ and examined for the capacity to upregulate surface expression of MHC class II. (C). Expression of MHC class II by DC in response to TNF- $\alpha$ could be restored if MSC were removed. Results are mean ( \pm S.E.) of triplicate data $(n=3)$, from a minimum of three experiments. Cells remained viable throughout culture and no induction of apoptosis was detected in this or subsequent experiments.

or maintain DC with an immature or "suppressor" phenotype, but this condition is not permanent and regular DC maturation can be restored in the absence of MSC (Fig. 1C).

\subsection{Murine MSC interfere with dendritic cell antigen presentation}

DC maturation involves a switch from antigen acquisition to antigen processing and presentation, a process that is broader than merely MHC class II, and CD86 upregulation. Interference in this process is likely to hamper antigen presentation, since co-stimulatory molecules are essential for optimal antigen presentation to naive $\mathrm{CD}^{+} \mathrm{T}$ cells. In order to investigate the influence of MSC on antigen presentation, an antigen-specific proliferation assay was performed using DO11.10 CD $4^{+} \mathrm{T}$ cells bearing the transgenic $\mathrm{T}$ cell receptor specific for the ovalbumin (OVA) peptide 323-339. This model was chosen to allow defined epitope effects to be studied and to avoid confounding effects 
Table 1

MSC but not transformed epithelial cells prevent DC upregulation of maturation markers

\begin{tabular}{lrrcr}
\hline Marker & \multicolumn{4}{c}{ Expression (mean fluorescence intensity) } \\
\cline { 2 - 5 } & iDC & mDC & mDC + MSC & mDC + MLE \\
\hline CD11c & 48 & 63 & 69 & 52 \\
MHC II & 539 & 601 & 410 & 990 \\
CD86 & 44 & 68 & 46 & 78
\end{tabular}

${ }^{a} \mathrm{CD} 11 \mathrm{c}, \mathrm{MHC}$ class II and CD86 expression were measured by flow cytometry of iDC, mDC, and TNF-a stimulated DC co-cultured with either MSC (mDC+MSC) or the transformed epithelial cell line MLE-12 (mDC+MLE). Data are presented as mean fluorescent intensity from a representative experiment of three replicates, 10,000 events were sampled in each case.

of allogenicity possible in other systems. Whole OVA pulsed DC derived from non-transgenic haploidentical bone marrow, efficiently supported antigen-specific DO11.10 CD4 ${ }^{+} \mathrm{T}$ cell proliferation (Fig. 2A). However, when DC were cultured in the presence of antigen and MSC, $\mathrm{CD}^{+} \mathrm{T}$ cell proliferation was partially but significantly reduced (Fig. 2A). The use of whole OVA protein, as opposed to specific peptide in these studies indicated that full antigen processing is occurring and eliminated the possibility of auto-presentation of peptide in a $\mathrm{T}$ cell to $\mathrm{T}$ cell manner.

T cell proliferation is a complex system and reductions might be occurring through other mechanisms. The effect of MSC on specific antigen presentation by DC was therefore analysed by a well-defined antigen presentation system taking advantage of the YAe antibody [35]. This antibody recognises a complex com- posed of I-E $\alpha$ peptide bound to I-A $\mathrm{A}^{\mathrm{b}}$ MHC class II molecules. C57/BL6 DC were chosen for these studies because this strain express I-A ${ }^{b}$ but not I-E and therefore would not constitutively express the I-E $\alpha$ : I-A ${ }^{\mathrm{b}}$ MHC class II complex [36]. C57/BL6 DC pulsed with I-E $\alpha$ peptide displayed the peptide: MHC II complex at the cell surface as determined by recognition of the fluorescently labelled YAe antibody (Fig. 2B). However, this was reduced when DC had been co-cultured with MSC (Fig. 2B), whereas controls consisting of iDC alone or iDC pulsed with vehicle buffer in the presence of MSC did not display the peptide: MHC II complex. Taken together these data confirm a role for MSC interference in antigen presentation by DC.

\subsection{Murine MSC prevent dendritic cell migration ability to CCL19}

DC maturation is accompanied by an alteration in the expression of chemokine receptors and other surface markers reflecting the requirement of maturing DC to migrate to regional lymph nodes. The three most striking of these alterations are: (1) the acquisition of CCR7 surface expression by mature DC; (2) a consequent capacity to migrate to CCL19 not seen in immature DC [17]; and (3) the loss of expression of the epithelial anchoring protein E-cadherin. Consequently, the effect of MSC on CCR7 expression and chemotactic ability by DC was investigated. DC cultured in the presence of MSC and stimulated with TNF- $\alpha$ exhibited reduced CCR7 mRNA (Fig. 3A), and reduced surface protein expression (Fig. 3B) when compared to regular TNF$\alpha$ matured DC. Similarly, an examination of the chemotactic

$$
\text { (A) }
$$

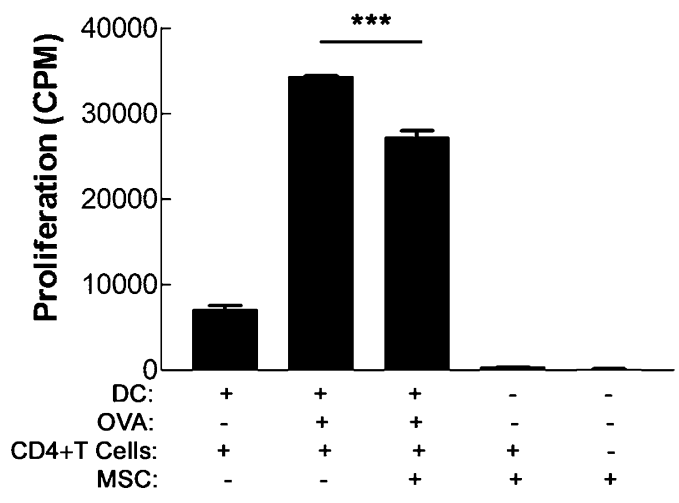

(B)
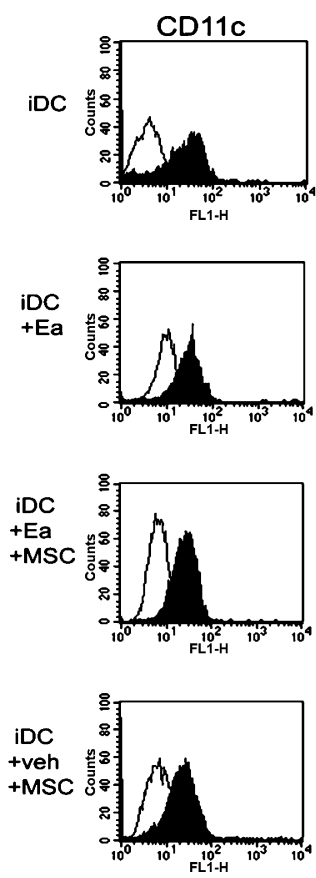
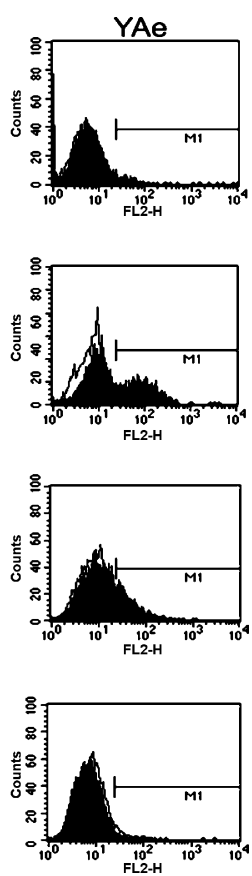

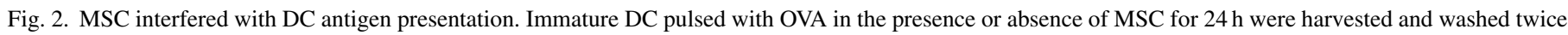

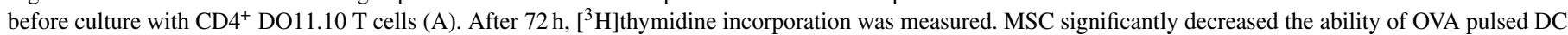

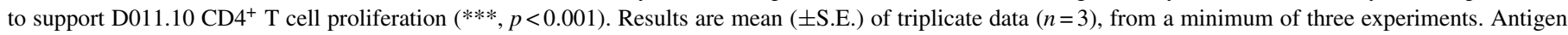

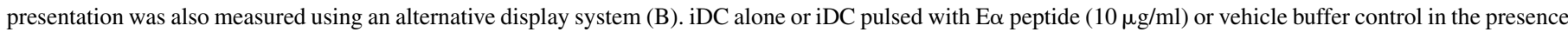

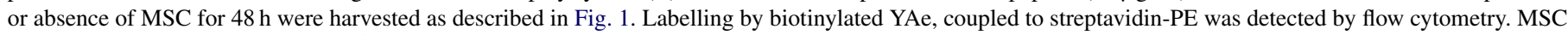
reduced DC presentation of I-E $\alpha: I-A^{b}$ MHC class II peptide complex detected by of YAe. Results are representative of two replicates in this instance. 
(A)

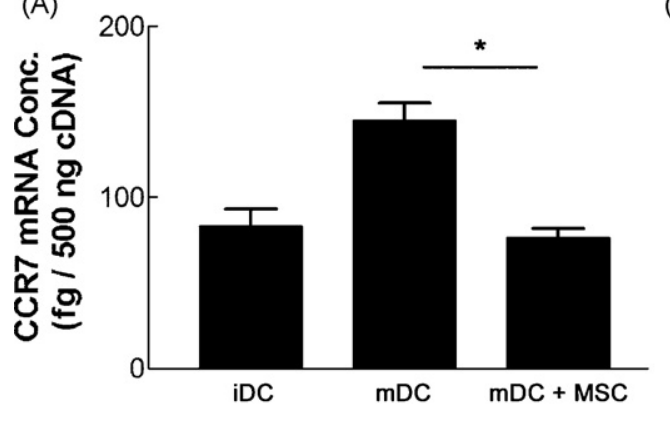

(B) Isotype control

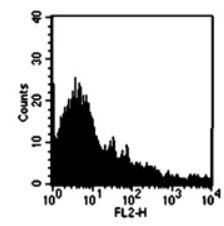

iDC

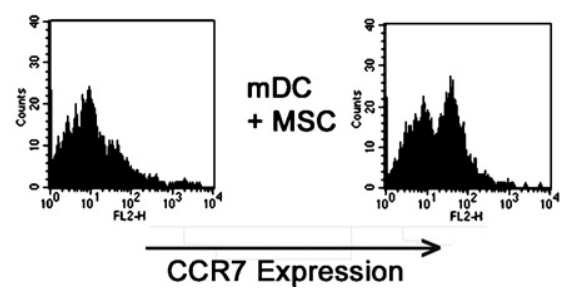

Fig. 3. Murine MSC downregulated CCR7 mRNA and surface protein expression by mature DC. (A) CCR7 mRNA was determined by quantitative real time RT-PCR at $24 \mathrm{~h}$ from immature DC or TNF- $\alpha$ stimulated DC cultured in the presence or absence of MSC. CCR7 mRNA expression by stimulated DC was significantly lower when cultured with MSC $(*, p<0.05)$. (B) CCR7 expression by iDC, TNF- $\alpha$ stimulated DC (mDC) or mDC cultured with MSC (mDC + MSC) was examined by flow cytometry with isotype-matched controls for comparison. MSC reduced CCR7 surface expression by TNF- $\alpha$ matured DC at $48 \mathrm{~h}$. Results are mean ( \pm S.E.) of triplicate data $(n=3)$, from a minimum of three experiments.

response revealed that DC co-cultured with MSC displayed significantly reduced capacity to migrate to CCL19, the lymph node expressed chemokine ligand for CCR7 (Fig. 4A). This reduction was not permanent, as removal of the DC from MSC co-cultures and subsequent re-stimulation with TNF- $\alpha$ restored the capacity of DC to migrate to CCL19 (Fig. 4B) and again confirmed that these were not affects attributable to medium exhaustion.

For effective relocation, mature DC must not only become responsive to lymph node derived signals, but must also downregulate tissue anchoring proteins $[18,37,38]$. The most prominent of such proteins is E-cadherin. E-cadherin has been reported to play an important role in interactions between immature Langerhans cells and skin tissue $[18,37,38]$. Upon maturation, Langerhans cells downregulate the anchor protein E-cadherin in order to migrate to the local lymph node [38]. The influence of MSC on E-cadherin was therefore examined. In co-culture experiments, MSC prevented downregulation of E-cadherin mRNA expression in TNF- $\alpha$ stimulated DC, as measured by semi-quantitative and quantitative real time PCR (Fig. 5A and B). This was reflected in E-cadherin protein expression, as detected by immunoblot, which was similar to that of immature DC and greater than that observed in mature DC (Fig. 5C). Taken together these data indicate that MSC influence DC maturation to prevent loss of tissue anchor proteins and limit acquisition of responsiveness to lymph node derived signals.

\section{Discussion}

This study demonstrates that MSC interfered with the three cardinal aspects of DC maturation. DC matured with TNF- $\alpha$ and cultured in the presence of MSC failed to show upregulation of the maturation marker CD86 and did not increase MHC class II surface expression. Furthermore, MSC suppressed the capacity of DC to support antigen specific proliferation by $\mathrm{T}$ cells and interfered with the display of specific peptide:MHC complex by DC as measured using the E $\alpha$ presentation system. In addition this study demonstrated for the first time that MSC preserve DC expression of tissue anchoring proteins, prevent
(A)

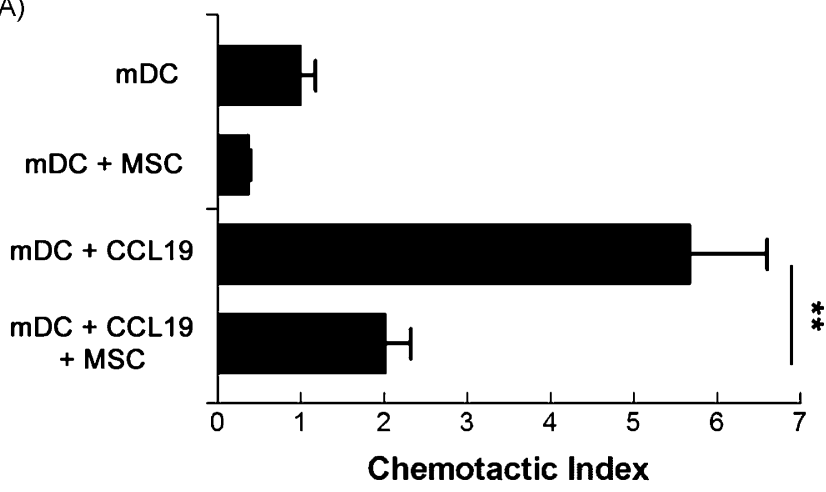

(B)

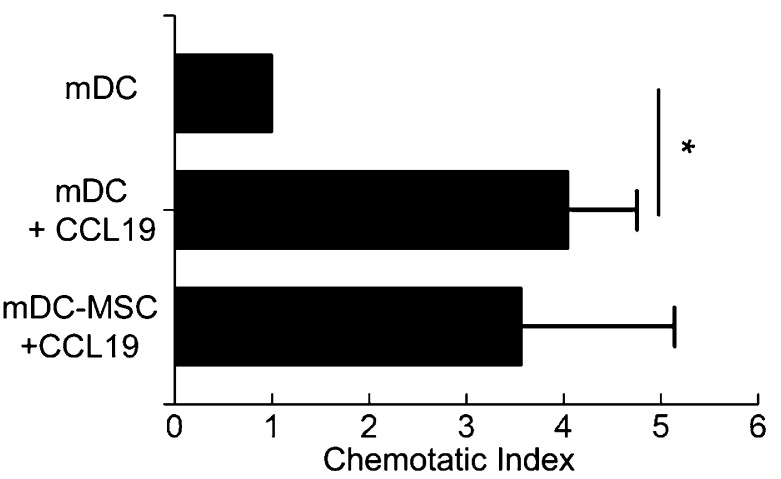

Fig. 4. Murine MSC interfered with DC migration toward CCL19. The ability of DC matured with TNF- $\alpha$ in the presence or absence of MSC for $48 \mathrm{~h}$ to migrate toward CCL19 was examined (A). TNF- $\alpha$ stimulated DC co-cultured in the presence of MSC displayed a significantly reduced chemotactic response to CCL19 compared to mature DC alone $(* *, p<0.01)$. Chemotactic ability was not permanently compromised (B). DC previously co-cultured with MSC, removed from MSC co-cultures and re-stimulated with TNF- $\alpha$ for $48 \mathrm{~h}$ migrated towards CCL19. Data are expressed as chemotactic index calculated against the basal level of mature DC migration to medium alone. Results are mean ( \pm S.E.) of counts determined from three random fields of view in duplicate chambers $(n=2)$, data shown is representative from a minimum of three independent experiments. 
(A)

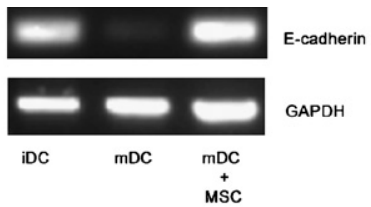

(C)

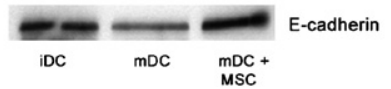

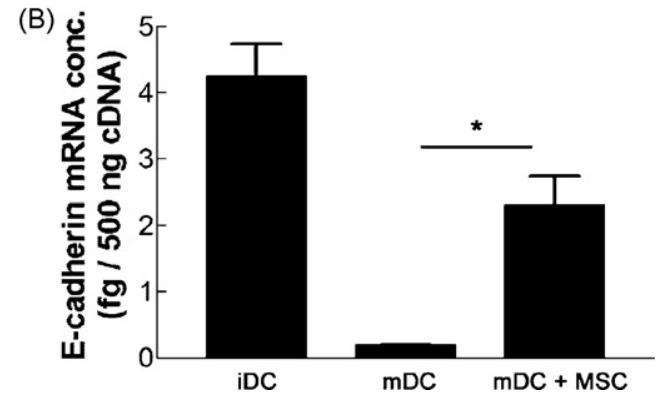

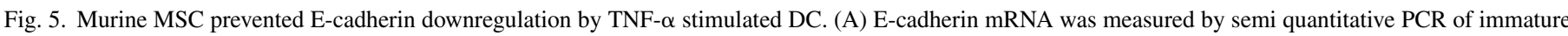

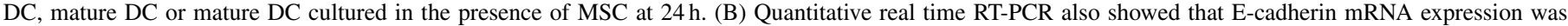

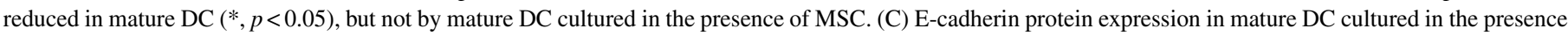

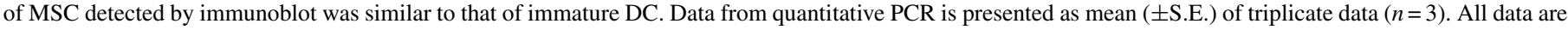
representative of a minimum of three experiments.

CCR7 chemokine receptor expression and reduce the migration capacity of DC to lymph node derived chemokines.

Modulation or prevention of DC maturation is a welldescribed observation but remains poorly characterised. It is known that immature or so-called "semi-mature" DC have immunosuppressive or regulatory characteristics. This has been best characterised in infectious disease models. For example, Influenza virus hemagglutinin (HA) and a virulence factor from Bordetella pertussis filamentous hemagglutinin (FHA) have been shown to modulate DC maturation marker expression $[19,20]$ reduce IL-12 production [20] and induce IL-10 induction [19]. The present study using TNF- $\alpha$ driven maturation, studies by Nauta et al. [22] using CD40L and especially those of Djouad et al. [39] using LPS clearly demonstrate that MSC influence DC to maintain or adopt a similar phenotype. This is consistent with previous studies that have demonstrated that MSC constitutively express TGF- $\beta 1$, and $\mathrm{HGF}[7,8,40]$ and with our previous demonstration that IFN- $\gamma$ enhanced MSC immunomodulation $[7,12]$. The present study suggests that MSC maintain DC with an immature or "semi-mature" suppressor phenotype [38] which contributes to the immunosuppressive capacity of MSC.

The mechanisms of MSC modulation of DC maturation have yet to be elucidated fully. However, studies by Djouad et al. [39] have demonstrated a role for IL-6 in MSC modulation of maturation marker expression. A possible role for IL-6 had also been alluded to by Nauta et al. [22] in 2006. Similar neutralisation studies in our system confirmed that MSC derived IL-6, but not HGF or TGF- $\beta 1$ prevented upregulation of DC maturation marker expression (data not shown). These data concerning MSC modulation of DC are in contrast to MSC modulation of allo-antigen driven responses measured in MLR which are mediated by MSC derived PGE-2 and in some circumstances by indoleamine 2,3, dioxygenase expression [7,12,41-43]. Thus, MSC modulate diverse aspects of the adaptive immune response through multiple different mechanisms.

In addition to modulation of DC maturation markers, MSC interfered with DC antigen presentation ability as demonstrated here using an antigen specific $\mathrm{T}$ cell proliferation assay and specific peptide:MHC II antigen display. Although MSC significantly interfered with DC presentation of ovalbumin to DO11.10 $\mathrm{CD}^{+} \mathrm{T}$ cells, the inhibition of antigen presentation was only partial. There are a number of possible explanations for this. It may be that a monoclonal DO11.10 CD4+ $\mathrm{T}$ cell response to ovalbumin presented by DC is less susceptible to suppression than polyclonal or wildtype populations, or that multiple mechanisms contribute to overall suppression and reduction and antigen display is only one contributory factor. In studies by Jiang et al. focusing on monocyte to DC differentiation, human allogeneic MSC were shown to hamper antigen presentation by DC in a keyhole-limpet hemocyanin (KLH) antigen specific T cell model. Allogeneic MSC downregulated both antigen presentation and IL-12 expression by DC [21]. Although the DO11.10 system used here might be less susceptible to immunosuppression by MSC, the use of a well-defined antigen and transgenic $\mathrm{T}$ cell model avoided the potentially confounding effect of allogenicity. Furthermore, the use of whole OVA protein, as opposed to specific peptide, indicated that full antigen processing is occurring rather than "bystander" presentation of peptide in a T cell to T cell manner. Nevertheless T cell proliferation is a complex interaction and may not be a straightforward marker of APC activity, therefore the E $\alpha$ antigen display system was employed to confirm that Ag-peptide display at the DC surface was reduced by MSC co-culture. These findings and those of Jiang et al. [21] lead to the conclusion that MSC reduce the APC function of DC and that this is not related to allogenicity, but involves modulation of DC antigen presentation machinery.

DC ability to migrate to the local lymph nodes and the subsequent presentation of antigen to $T$ cells play an essential role in initiation of adaptive immunity [44]. In tissues, mature DC must become responsive to lymph node derived signals, but must also downregulate tissue anchoring proteins such as E-cadherin $[18,37,38]$ that would otherwise veto DC migration and antigen presentation to naïve $\mathrm{T}$ cells. This study provided the first indication that this process is modulated by MSC, such that DC exposed to TNF- $\alpha$ failed to downregulate E-cadherin. Likewise, the expression of the chemokine receptor CCR7 by mature DC plays an important role in DC migration to lymph node derived chemokines such as CCL19. MSC significantly reduced both CCR7 surface expression by DC and the functional migration to CCL19. Together, these data show that MSC interfered with key aspects of DC migration. The implications of these findings are that sites of repair where MSC are present (or tissues targeted 
in regenerative medicine) should either display an accumulation of immature DC, or reduce DC recruitment to draining lymph nodes. We are currently examining that question, but intriguingly it suggests that MSC may have an additional application as an immunosuppressive therapy in autoimmune disease.

The ability of MSC to suppress alloreactivity has now been characterised by a number of groups [7-10], however, the need for MSC to possess this activity has been perplexing. The influence of MSC on DC shown here may partially resolve this problem. Firstly, both immature DC and MSC are normally resident in the bone marrow. The capacity for MSC to veto DC function would help impede premature maturation of DC, prior to DC exit from the bone marrow. Secondly, the main role of adult MSC is in tissue repair. This process is de facto part of the resolution phase that follows physiological or microbial insult. Therefore, whilst DC maturation needs to be promoted during inflammatory events, MSC mediated resolution would favour a non-inflammatory environment and preservation of DC immaturity. The ability of MSC to modulate the three major aspects of DC maturation shown herein is consistent with that hypothesis.

\section{Acknowledgements}

This work was supported by Science Foundation Ireland Centres for Science Engineering and Technology for the Regenerative Medicine Institute (REMEDI). Dr. Joanne Masterson is thanked for assistance with Western blot. Dr. Christine Loscher is thanked for advice on dendritic cell culture.

\section{References}

[1] Barry FP. Biology and clinical applications of mesenchymal stem cells. Birth Defects Res C Embryo Today 2003;69:250-6.

[2] Pittenger MF, Mackay AM, Beck SC, Jaiswal RK, Douglas R, Mosca JD, et al. Multilineage potential of adult human mesenchymal stem cells. Science 1999;284:143-7.

[3] Haynesworth SE, Baber MA, Caplan AI. Cytokine expression by human marrow-derived mesenchymal progenitor cells in vitro: effects of dexamethasone and IL-1 alpha. J Cell Physiol 1996;166:585-92.

[4] Horwitz EM, Prockop DJ, Fitzpatrick LA, Koo WW, Gordon PL, Neel $\mathrm{M}$, et al. Transplantability and therapeutic effects of bone marrow-derived mesenchymal cells in children with osteogenesis imperfecta. Nat Med 1999;5:309-13.

[5] Koc ON, Day J, Nieder M, Gerson SL, Lazarus HM, Krivit W. Allogeneic mesenchymal stem cell infusion for treatment of metachromatic leukodystrophy (MLD) and Hurler syndrome (MPS-IH). Bone Marrow Transplant 2002;30:215-22.

[6] Murphy JM, Fink DJ, Hunziker EB, Barry FP. Stem cell therapy in a caprine model of osteoarthritis. Arthritis Rheum 2003;48:3464-74.

[7] English K, Barry FP, Field-Corbett CP, Mahon BP. IFN-gamma and TNFalpha differentially regulate immunomodulation by murine mesenchymal stem cells. Immunol Lett 2007;110:91-100.

[8] Di Nicola M, Carlo-Stella C, Magni M, Milanesi M, Longoni PD, Matteucci P, et al. Human bone marrow stromal cells suppress T-lymphocyte proliferation induced by cellular or nonspecific mitogenic stimuli. Blood 2002;99:3838-43.

[9] Glennie S, Soeiro I, Dyson PJ, Lam EW, Dazzi F. Bone marrow mesenchymal stem cells induce division arrest anergy of activated $\mathrm{T}$ cells. Blood 2005;105:2821-7.

[10] Krampera M, Glennie S, Dyson J, Scott D, Laylor R, Simpson E, et al. Bone marrow mesenchymal stem cells inhibit the response of naive and memory antigen-specific T cells to their cognate peptide. Blood 2003;101:3722-9.
[11] Krampera M, Cosmi L, Angeli R, Pasini A, Liotta F, Andreini A, et al. Role for interferon-gamma in the immunomodulatory activity of human bone marrow mesenchymal stem cells. Stem Cells 2006;24:386-98.

[12] Ryan JM, Barry F, Murphy JM, Mahon BP. Interferon-gamma does not break, but promotes the immunosuppressive capacity of adult human mesenchymal stem cells. Clin Exp Immunol 2007;149:353-63.

[13] Augello A, Tasso R, Negrini SM, Amateis A, Indiveri F, Cancedda R, et al. Bone marrow mesenchymal progenitor cells inhibit lymphocyte proliferation by activation of the programmed death 1 pathway. Eur J Immunol 2005;35:1482-90.

[14] Spaggiari GM, Capobianco A, Becchetti S, Mingari MC, Moretta L. Mesenchymal stem cell-natural killer cell interactions: evidence that activated NK cells are capable of killing MSCs, whereas MSCs can inhibit IL-2induced NK-cell proliferation. Blood 2006;107:1484-90.

[15] Banchereau J, Steinman RM. Dendritic cells and the control of immunity. Nature 1998:392:245-52.

[16] Kawai T, Akira S. Pathogen recognition with Toll-like receptors. Curr Opin Immunol 2005;17:338-44.

[17] Sanchez-Sanchez N, Riol-Blanco L, de la Rosa G, Puig-Kroger A, Garcia-Bordas J, Martin D, et al. Chemokine receptor CCR7 induces intracellular signaling that inhibits apoptosis of mature dendritic cells. Blood 2004;104:619-25.

[18] Jakob T, Udey MC. Regulation of E-cadherin-mediated adhesion in Langerhans cell-like dendritic cells by inflammatory mediators that mobilize Langerhans cells in vivo. J Immunol 1998;160:4067-73.

[19] McGuirk P, McCann C, Mills KH. Pathogen-specific T regulatory 1 cells induced in the respiratory tract by a bacterial molecule that stimulates interleukin 10 production by dendritic cells: a novel strategy for evasion of protective T helper type 1 responses by Bordetella pertussis. J Exp Med 2002;195:221-31.

[20] Noone CM, Lewis EA, Frawely AB, Newman RW, Mahon BP, Mills KH, et al. Novel mechanism of immunosuppression by influenza virus haemagglutinin: selective suppression of interleukin $12 \mathrm{p} 35$ transcription in murine bone marrow-derived dendritic cells. J Gen Virol 2005;86:1885-90.

[21] Jiang XX, Zhang Y, Liu B, Zhang SX, Wu Y, Yu XD, et al. Human mesenchymal stem cells inhibit differentiation and function of monocytederived dendritic cells. Blood 2005;105:4120-6.

[22] Nauta AJ, Kruisselbrink AB, Lurvink E, Willemze R, Fibbe WE. Mesenchymal stem cells inhibit generation and function of both CD34+-derived and monocyte-derived dendritic cells. J Immunol 2006;177:2080-7.

[23] Zhang W, Ge W, Li C, You S, Liao L, Han Q, et al. Effects of mesenchymal stem cells on differentiation, maturation, and function of human monocytederived dendritic cells. Stem Cells Dev 2004;13:263-71.

[24] Beyth S, Borovsky Z, Mevorach D, Liebergall M, Gazit Z, Aslan H, et al. Human mesenchymal stem cells alter antigen-presenting cell maturation and induce T-cell unresponsiveness. Blood 2005;105:2214-9.

[25] Anjos-Afonso F, Siapati EK, Bonnet D. In vivo contribution of murine mesenchymal stem cells into multiple cell-types under minimal damage conditions. J Cell Sci 2004;117:5655-64.

[26] Stagg J, Pommey S, Eliopoulos N, Galipeau J. Interferon-gammastimulated marrow stromal cells: a new type of nonhematopoietic antigen-presenting cell. Blood 2006;107:2570-7.

[27] Djouad F, Plence P, Bony C, Tropel P, Apparailly F, Sany J, et al. Immunosuppressive effect of mesenchymal stem cells favors tumor growth in allogeneic animals. Blood 2003;102:3837-44.

[28] Murphy KM, Heimberger AB, Loh DY. Induction by antigen of intrathymic apoptosis of CD4+CD8+TCRlo thymocytes in vivo. Science 1990;250:1720-3.

[29] Peister A, Mellad JA, Larson BL, Hall BM, Gibson LF, Prockop DJ. Adult stem cells from bone marrow (MSCs) isolated from different strains of inbred mice vary in surface epitopes, rates of proliferation, and differentiation potential. Blood 2004;103:1662-8.

[30] Inaba K, Inaba M, Romani N, Aya H, Deguchi M, Ikehara S, et al. Generation of large numbers of dendritic cells from mouse bone marrow cultures supplemented with granulocyte/macrophage colony-stimulating factor. J Exp Med 1992;176:1693-702.

[31] Lutz MB, Kukutsch N, Ogilvie AL, Rossner S, Koch F, Romani N, et al. An advanced culture method for generating large quantities of highly pure 
dendritic cells from mouse bone marrow. J Immunol Methods 1999;223: $77-92$.

[32] Mahon BP, Sheahan BJ, Griffin F, Murphy G, Mills KH. Atypical disease after Bordetella pertussis respiratory infection of mice with targeted disruptions of interferon-gamma receptor or immunoglobulin mu chain genes. J Exp Med 1997;186:1843-51.

[33] Bouma G, Coppens JM, Mourits S, Nikolic T, Sozzani S, Drexhage HA, et al. Evidence for an enhanced adhesion of DC to fibronectin and a role of CCL19 and CCL21 in the accumulation of DC around the pre-diabetic islets in NOD mice. Eur J Immunol 2005;35:2386-96.

[34] Honey K, Forbush K, Jensen PE, Rudensky AY. Effect of decreasing the affinity of the class II-associated invariant chain peptide on the MHC class II peptide repertoire in the presence or absence of H-2M. J Immunol 2004;172:4142-50.

[35] Rudensky A, Rath S, Preston-Hurlburt P, Murphy DB, Janeway Jr CA. On the complexity of self. Nature 1991;353:660-2.

[36] Murphy DB, Rath S, Pizzo E, Rudensky AY, George A, Larson JK, et al. Monoclonal antibody detection of a major self peptide. MHC class II complex. J Immunol 1992;148:3483-91.

[37] Tang A, Amagai M, Granger LG, Stanley JR, Udey MC. Adhesion of epidermal Langerhans cells to keratinocytes mediated by E-cadherin. Nature 1993;361:82-5.
[38] Lutz MB, Schuler G. Immature, semi-mature and fully mature dendritic cells: which signals induce tolerance or immunity? Trends Immunol 2002;23:445-9.

[39] Djouad F, Charbonnier LM, Bouffi C, Louis-Plence P, Bony C, Apparailly $\mathrm{F}$, et al. Mesenchymal stem cells inhibit the differentiation of dendritic cells through an interleukin-6-dependent mechanism. Stem Cells 2007;25:2025-32.

[40] Barry FP, Murphy JM, English K, Mahon BP. Immunogenicity of adult mesenchymal stem cells: lessons from the fetal allograft. Stem Cells Dev 2005;14:252-65.

[41] Meisel R, Zibert A, Laryea M, Gobel U, Daubener W, Dilloo D. Human bone marrow stromal cells inhibit allogeneic T-cell responses by indoleamine 2,3-dioxygenase-mediated tryptophan degradation. Blood 2004;103:4619-21.

[42] Aggarwal S, Pittenger MF. Human mesenchymal stem cells modulate allogeneic immune cell responses. Blood 2005;105:1815-22.

[43] Rasmusson I, Ringden O, Sundberg B, Le Blanc K. Mesenchymal stem cells inhibit lymphocyte proliferation by mitogens and alloantigens by different mechanisms. Exp Cell Res 2005;305:33-41.

[44] Del Prete A, Vermi W, Dander E, Otero K, Barberis L, Luini W, et al. Defective dendritic cell migration and activation of adaptive immunity in PI3Kgamma-deficient mice. EMBO J 2004;23:3505-15. 